\title{
Embates na definição das políticas de formação de professores para a atuação multidisciplinar nos anos iniciais do Ensino Fundamental: Respeito à cidadania ou disputa pelo poder?
}

\author{
Iria Brzezinski *
}

\begin{abstract}
RESUMO: O artigo situa os embates contemporâneos travados entre o mundo oficial e o mundo real em relação às políticas de formação de professores para a educação básica, em particular, às políticas de formação de professores das séries iniciais do Ensino Fundamental. Nele buscam-se alternativas para a indagação: esses embates expressam respeito à cidadania ou constituem disputa pelo poder? Tal busca requereu uma incursão na história das políticas, das instituições (loci) e dos cursos que, na modalidade regular, vêm formando professores para atuar multidisciplinarmente no Ensino Fundamental em nosso país. Concomitantemente, foi necessária uma fundamentação em aportes teóricos que tratam das relações de poder presentes na sociedade e na escola brasileiras, as quais convivem com a existência de dois mundos bem definidos: um mundo do sistema e um outro, do vivido. Tal dicotomia é própria das sociedades modernas e pressupõe um jogo de interações entre esses mundos, consistindo em uma luta poderosa e dinâmica entre a coerção da sociedade política e a resistência ativa da sociedade civil.
\end{abstract}

Palavras-chave: Políticas de formação de professores, professor das séries iniciais do Ensino Fundamental, atuação multidisciplinar, mundo do sistema, mundo real

* Professora titular da Universidade Católica de Goiás (UCG), pesquisadora associada da Universidade de Brasília (UnB) e ex-presidente da Associação Nacional pela Formação dos Profissionais da Educação (Anfope). Email: iria@netgo.com.br 
... A realidade, porém, é que nos acostumamos a viver em dois planos, o real com suas particularidades e originalidades e $o$ oficial com seus reconhecimentos convencionais de padrões inexistentes. Continuamos a ser, com a autonomia, a nação de dupla personalidade, a oficial e a real.

Anísio Teixeira

\section{Primeiras considerações}

O Decreto Presidencial $n^{0} 3.276$, de 6/12/99, que "dispõe sobre a formação de professores para atuar na educação básica, e dá outras providências", é uma verdadeira manifestação de como o mundo oficial atribui padrões para o mundo real (ou mundo vivido) dos profissionais da escola básica, sem levar em conta suas particularidades e originalidades, advindas sobretudo de saberes que Ihes são próprios.

Ignorando a realidade do cotidiano dos professores e seus saberes, - Decreto Presidencial supracitado prescreve, entre outras coisas, que "a formação em nível superior de professores para atuação multidisciplinar, destinada ao magistério na Educação Infantil e nos anos iniciais do Ensino Fundamental, far-se-á exclusivamente em cursos normais superiores" (art. $\left.3^{\circ}, \S 2^{\circ}\right)$.

Não só tal prescrição, como as demais contidas no decreto - de modo geral, tão distantes dos ideais sustentados pelos profissionais da educação - são, com certeza, decorrentes do propósito do mundo do sistema de obedecer cegamente aos preceitos do neoliberalismo e aos financiadores externos que vêm impondo reformas educacionais aos países da América Latina, no intuito de que estes ingressem na lógica do mundo globalizado. O "mandante financeiro" dessas reformas é o Banco Mundial.

Em face dos ditames desse órgão financeiro internacional, o Brasil tem adotado um "modelo" de formação de professores que consiste muito mais em conceder uma certificação do que conferir uma boa qualificação aos leigos atuantes no sistema educacional e aos futuros professores. Os resultados desse "modelo" têm sido expressos por dados quantitativos ${ }^{1}$ que pretendem causar impacto nos financiadores externos das políticas educacionais, o que está longe de representar a política global de formação e de profissionalização para o magistério defendida pelo mundo vivido do Movimento Nacional de Educadores, hoje Anfope. 
É interessante notar que essas imposições, consideradas inadequadas para o país, atingem não só a área educacional, mas também a área econômica, conforme revela uma análise do caso brasileiro feita por Bresser Pereira (Folha de S. Paulo, 20/12/99) sobre o estado de dependência dos países latino-americanos à política do Banco Mundial. Ele assim se pronuncia: "decisões equivocadas, tomadas geralmente com apoio de Washington e Nova York, a quem se queria agradar a todo custo para alcançar 'credibilidade', explicam em grande parte a quase estagnação latino-americana" (C1, F3; grifos meus). Confesso que, com essa afirmação, fica difícil discernir de que lado se coloca o ex-ministro da Ciência e Tecnologia e da Administração do governo Fernando Henrique Cardoso, pois, quando esteve respondendo pelas duas pastas, deu mostras de que estava sempre do lado do mundo do sistema ao tomar medidas prejudiciais ao desenvolvimento da pesquisa nas universidades públicas, à qualificação e à valorização dos servidores públicos federais, sobretudo dos professores universitários.

A meu ver, Bresser Pereira assumia atitudes tão autoritárias quanto as dos assessores do "professor" e sociólogo Fernando Henrique Cardoso que respondem pelo Ministério da Educação - MEC. Atendendo às solicitações desses assessores, o Presidente da República baixou o citado decreto, demonstrando desrespeito pelos educadores que têm se dedicado sistematicamente aos estudos e pesquisas sobre formação de professores. A atitude do Presidente da República, ao "decretar" como e onde se deve formar o professor de atuação multidisciplinar no magistério da Educação Infantil e nos anos iniciais do Ensino Fundamental, desconsiderou os resultados das pesquisas e experiências já realizadas e violentou o direito dos educadores, autoridades teórico-práticas da área, de democraticamente oferecer suas contribuições sobre 0 assunto.

Não é demais reiterar o alerta feito por mim, desde 1994, de que os movimentos sociais de educadores necessitam manter a vigilância sobre o Estado, a fim de que políticas educacionais não sejam definidas nos gabinetes. Lamentavelmente, mais uma vez, a tensão entre as forças sociais confirma o excessivo poder do Estado, manifestado por mais um ato antidemocrático que privilegia a "fogueira de vaidades" acesa nos bastidores do MEC e se volta contra os interesses coletivos dos professores.

A força do decreto no 3.276/99 golpeou o histórico Movimento Nacional de Educadores, que se dedica há duas décadas, de forma científica e acadêmica, aos debates, aos estudos e ao desenvolvimento de pesquisas e de experiências sobre a formação de profissionais para a edu- 
cação básica, nas faculdades de educação e nos institutos de conteúdos "específicos" ou similares, nos quais se localizam as licenciaturas plenas.

O que é evidente nas atuais políticas educacionais de formação de professores é que, apesar de a educação básica do brasileiro ter tomado lugar central no discurso oficial e no dos detentores do capital, as ações do governo são de desvalorização do papel social e cultural dos profissionais da educação, e de desmantelamento das estruturas das instituições superiores responsáveis pela formação de professores.

Além das sucessivas medidas que levam à desvalorização dos profissionais da educação e ao sucateamento das instituições superiores públicas voltadas para a formação de professores, o governo insiste em apontar o despreparo dos professores como a única causa do fraco desempenho dos estudantes, comprovado pela avaliação efetivada pelo Sistema Nacional de Avaliação da Educação Básica do Instituto Nacional de Estudos e Pesquisas Educacionais (Saeb/Inep).

Não que o mundo real dos professores deixe de reconhecer a necessidade de mudanças para melhorar o preparo dos profissionais que atuam e dos que irão atuar na educação básica, ou que o mundo vivido se coloque em uma radical posição maniqueísta, para a qual seria totalmente negativo tudo o que pudesse advir do mundo oficial. Ao contrário, os educadores fazem severas críticas ao modelo atual de formação, que não corresponde às exigências da sociedade do conhecimento, marcada por inovações tecnológicas. Não aceitam, porém, que o mundo do sistema alegue que o despreparo dos professores seja a única causa dos insucessos dos estudantes. Somam-se a essa inverdade as ações governamentais do MEC, ao interferir nas estruturas das instituições superiores que formam professores, sobretudo das universidades públicas, sob a acusação de que têm sido improdutivas e incompetentes para consolidar uma formação de professores que responda aos desafios da sociedade contemporânea.

Diante dessas considerações introdutórias, indago: os embates travados entre o mundo oficial e o mundo real em relação às políticas de formação de professores para a educação básica expressam respeito à cidadania ou constituem disputa pelo poder?

Para centrar o debate nessa questão, que consiste o objetivo deste artigo, é preciso fazer uma incursão na história das políticas, das instituições e dos cursos que, de modo regular, vêm formando professores para as séries iniciais do Ensino Fundamental em nosso país, o que farei logo a seguir. É necessária, concomitantemente, uma fundamentação em aportes te- 
óricos que tratem das relações de poder presentes na sociedade e na escola brasileiras que, como já afirmei, convivem com a existência de dois mundos bem definidos: um mundo do sistema e um outro - o real. Essa duplicidade, segundo Teixeira (1969), é própria das sociedades modernas. No meu entendimento, essa dicotomia pressupõe um jogo de interações entre os dois mundos, consistindo de uma luta poderosa e dinâmica entre a coerção da sociedade política e a resistência ativa da sociedade civil ${ }^{2}$.

\section{Políticas, instituições (loci) e cursos de formação de professores de atuação multidisciplinar nas séries iniciais do Ensino Fundamental: A história revisitada}

Mostrar o movimento das políticas, das instituições (locl) e dos cursos de formação do professor para as séries iniciais do Ensino Fundamental, mediante uma incursão pela história da educação brasileira, requer especialmente voltar ao século XIX. Significa descobrir que a Escola Normal instalada naquele século foi o locus formal e obrigatório, de nível médio, de preparo dos professores "primários"3. É descobrir também que a existência da Escola Normal no Brasil durante o período imperial foi o resultado, em parte, de uma luta desigual entre o poder que exerciam os liceus, com o predomínio de estudos regulares elitistas para formar os jovens abastados do sexo masculino, e as "cadeiras de pedagogia ${ }^{4}$ anexas aos Liceus" (Chagas 1984, p. 23), destinadas aos que pretendiam ser professores "primários".

Voltar ao século XIX é constatar que, durante o Império, as Escolas Normais eram criadas primeiramente por decreto e que, por falta de condições de se estabelecerem como verdadeiros centros de referência de formação de professores, eram improvisadas para ser logo extintas e depois reabertas, "depois reextintas e novamente reabertas, numa interminável sucessão de avanços e recuos muito próprios daqueles dias". Algumas foram criadas nas províncias, mesmo antes da existência da do município da Corte (1880). São elas: as de Niterói (1835); da Bahia (1836), do Pará (1839), do Ceará (1845) e de São Paulo (1846) ${ }^{5}$.

A Escola Normal no município da Corte foi criada para "professores e professoras". Segundo Moacyr,

nessa escola são admitidos mediante módica pensão, os moços aspirantes ao professorado, tendo anexo, como curso de aplicação, 
uma escola modelo em que se exercitem na prática de ensino. Este estabelecimento deve ser organizado segundo o plano das escolas normais da Bélgica. (1938, pp. 329-330)

Voltar ao século XIX é descobrir certas verdades sobre a formação do professor das séries iniciais do Ensino Fundamental. Não se pode negar que o propósito de formar pessoal para o magistério "primário" esteve presente em todo o período imperial, por meio de decretos imperiais e provinciais. No entanto, não se pode negar também que, na prática, pouco foi feito. É, de fato, impressionante "o contraste entre a pequenez das realizações e a massa de decretos e projetos de lei (...), cerca de 40 os projetos mais importantes sobre a instrução pública" (Azevedo 1975, p. 92).

$\mathrm{Na}$ verdade, ao revisitar a formação de professores "primários" no século XIX descobri um fato marcante. A mim foi revelada a semelhança entre "a pequenez das realizações e a massa de decretos" do período imperial e a quantidade de medidas provisórias e decretos presidenciais e a frágil qualidade de realizações, a favor da população brasileira, de nosso governante de final do século XX. Outra revelação foi a descoberta da fonte inspiradora do presidente da República e de seus assessores do MEC para exercer o autoritarismo, fazendo uso do mesmo instrumento do período imperial que fora imposto de "cima para baixo". Essa fonte consiste na lei de 15 de outubro de 1827. Se, por um lado, essa lei tem o mérito de, em seu art. 10, ter prescrito a obrigatoriedade do "ensino das primeiras letras" para todos os cidadãos brasileiros com a criação de "escolas de primeiras letras" em todas as cidades, vilas e lugarejos mais populosos e instituir a didática oficial denominada ensino mútuo ${ }^{6}$, por outro, traduzia, com toda a radicalidade autoritária, a desobrigação do Estado com a formação de professores, em seu art. $5^{\circ}$, no qual se lê o seguinte: “(...) e os professores que não tiverem a necessária instrução desse ensino irão instruir-se em curto prazo e a custa de seus ordenados". Similarmente, se o Decreto $n^{\circ}$ 3.276/ 99, por um lado, tem o mérito de definir uma política de formação de professores para atuar na Educação Infantil e nos anos iniciais do Ensino Fundamental, por outro, desmerece as contribuições dos profissionais da educação que estudam, pesquisam e vivenciam a formação do professor das séries iniciais do Ensino Fundamental no curso de pedagogia.

Por ironia, a lei de 15 de outubro de 1827 marca, no Brasil, a data da comemoração do Dia do Professor. Pergunto: que comemoração o mundo do sistema pretende demarcar com o Decreto $n^{\circ} 3.276$ de 6 de dezembro de 1999? Seria a extinção das faculdades de educação das universidades? 
Ou estaria o mundo do sistema pretendendo mostrar sua força ao se colocar "numa relação social, mesmo contra resistências" (Weber 1991, p. 33)?

Os assessores do presidente que "governam o MEC" vêm se deparando com sérias resistências dos movimentos sociais de educadores, sobretudo de associações científicas que se preocupam com as políticas de formação de profissionais da educação. Minha experiência como militante nessas associações pode confirmar a resistência ativa de pelo menos três delas - a Anfope, a Anped e a Anpae. Essas associações vêm resistindo à transferência da formação de professores das séries iniciais do Ensino Fundamental do curso de pedagogia para as Escolas Normais Superiores e Institutos Superiores de Educação (ISEs), neste momento, imposta autoritariamente pelo Decreto nํㅜ 3.276/99.

É importante registrar que as mencionadas associações reconhecem algumas deficiências da formação que vem sendo feita nas faculdades de educação e em cursos de pedagogia de faculdades isoladas. No entanto, não podem aceitar uma represália do poder instituído no MEC, que faz questão de deixar de divulgar as experiências bemsucedidas de reformulação curricular dos cursos de pedagogia, que vêm ocorrendo em um conjunto significativo de instituições ${ }^{7}$. Tais experiências não têm tido ampla divulgação por falta de meios e de interesse político do MEC. Esse desinteresse é exemplar no pronunciamento da secretária da educação fundamental do ministério, em audiência pública sobre o Fundef, ao responder ao relator do Plano Nacional da Educação sobre a imposição dos ISEs como formadores de docentes de atuação multidisciplinar nas séries iniciais do Ensino Fundamental e na Educação Infantil. O relator indagava se existia uma pesquisa que comprovasse a eficácia desses institutos para formar docentes para os anos iniciais do Ensino Fundamental. A secretária respondeu que era de seu conhecimento o sucesso da experiência do Instituto Superior "Presidente Kennedy" de Natal (RN), desenvolvida em convênio com a Universidade Estadual de Mossoró. Com essa resposta, a representante do mundo oficial demonstrou desconhecer o que pesquisas já comprovaram a respeito, pois as universidades federais brasileiras adotaram, desde o final da década de 1980, a docência como base de formação do pedagogo, com ênfase na formação do professor das séries iniciais do Ensino Fundamental (Brzezinski 1996d, pp. 122-211).

Com efeito, a história da educação brasileira mostra-nos que desde o início do século XX já se pensava em uma formação de professores em níveis mais elevados de ensino, tanto é que no começo deste século 
foram desenvolvidas experiências em cursos pós-normais, instalados na Escola Normal da Praça, em São Paulo. Esses cursos de aperfeiçoamento de professores foram o germe dos cursos superiores de formação de profissionais da educação implantados por força do Estatuto da Universidade Brasileira e da reforma Francisco Campos, os quais, em 1931, elevaram ao nível superior a formação do professor secundário. A Escola Normal de então foi transformada em Instituto Pedagógico de São Paulo, e depois Instituto de Educação Caetano de Campos (1933). Em face das condições que oferecia, o Instituto Pedagógico passou a ter um caráter híbrido de escola de formação de professores, uma vez que conviviam no mesmo locus o Curso Normal que formava professores "primários" e o curso de aperfeiçoamento que formava especialistas em nível pós-normal, ou seja, destinava-se ao preparo técnico de inspetores, delegados de ensino, diretores e professores da Escola Normal.

Desse curso pós-normal, instalado no Instituto Pedagógico como um "substituto provisório para uma futura escola superior de estudos pedagógicos, quando houvesse condições para tanto" (Antunha 1974, p. 100), originou-se a Faculdade de Educação da USP. A partir de 1933, ampliaram-se as finalidades do curso de aperfeiçoamento, que começou a formar professores de nível secundário. A escola, então, passou a se denominar Escola de Professores do Instituto de Educação, que mais tarde seria incorporada pela USP. Entretanto, essa incorporação não significou avanços para a profissionalização docente. Ao se referir a ela, Fétizon (1986, p. 133) ressalta que "se tratou de uma incorporação sui generis, configurando, mesmo em termos legais, um nível superior de segunda categoria, dadas as discriminações que, de fato e de direito, marcaram o Instituto de Educação e o profissional do ensino secundário, na própria universidade e fora dela". Nessas afirmações há evidências do desprestígio que marca, até os dias atuais, os estudos destinados à formação de professores na universidade pública em relação às outras áreas do conhecimento. Em decorrência da hegemonia de áreas consideradas "mais nobres" científica e socialmente, foi se configurando uma resistência à formação de professores entre os próprios "cientistas" e "educadores" das duas primeiras universidades públicas no Brasil, a USP (SP/1934) e a Universidade do Distrito Federal - UDF (RJ/1935).

Diante dessas disputas pelo poder que desrespeitam qualquer direito de cidadania e se arrastam pela história das relações existentes na universidade, pergunto: como ficou a formação do professor "primário" nessa fase da história da educação no Brasil? 
Para tanto, detenho-me nas fecundas décadas de 1920 e 1930 que foram palco do movimento de modernização do ensino em nosso país - para captar, nesse período, as forças de representantes do Movimento dos Pioneiros da Escola Nova (1932) em defesa da formação de professores em nível superior, para atuarem em qualquer nível de ensino.

Os Pioneiros defendiam um sistema nacional de ensino, que sustentasse como princípios democráticos da educação escolar a escola única, laica e gratuita. Eles previam a inclusão, nesse sistema, da universidade concebida com uma tridimensionalidade de funções, quais sejam: de "elaboradora ou creadora de sciência", de "transmissora de conhecimentos" e de "popularizadora das sciências e das artes" (Manifesto dos Pioneiros 1984, p. 419). Ocorre que a intelectualidade brasileira, quando se tratava de eleger a prioridade entre as três funções, esteve dividida em dois segmentos - o dos "cientistas" e o dos "educadores".

Os estudos de Schwartzman (1979) apontam divergências entre os "cientistas" e os "educadores" dessa época. Estes defendiam como uma das funções principais da universidade a formação de professores e, aqueles, a da pesquisa. Como se fosse possível dissociar a pesquisa da formação de professores. Os "educadores" tinham uma concepção de professor análoga à concepção dos Pioneiros e defendiam uma escola comum e igual para todos, visando à unificação, respeitadas a diversidade e a especificidade de cada grau de ensino. Os Pioneiros enfatizavam que a formação universitária dos professores de todos os graus de ensino "não é somente uma necessidade, mas o único meio de, elevando-lhes em verticalidade a cultura, abrir-lhes a vida sobre todos os horizontes" (Manifesto dos Pioneiros 1984, p. 422) e de prepará-los para uma função pública da mais alta importância. Esses educadores baseiam-se no postulado da unificação, segundo o qual toda a formação dos professores primários e secundários deve ser realizada em escolas ou cursos universitários.

Esse princípio orientou a Escola de Professores do Instituto de Educação do Rio de Janeiro, incorporada por Anísio Teixeira à Universidade do Distrito Federal, em 1935. Esse "modelo" de Escola de Professores organizou-se, na UDF, com uma estrutura verticalizada de formação em uma única escola. Contudo, essa universidade teve existência breve, dada a perseguição feita ao seu idealizador que era tido como comunista. Pela sua destinação, a Universidade do Distrito Federal foi chamada por Mendonça (1993) de "Universidade de Educação" ou "Utopia Vetada". Universidade de Educação, pelo fato de ter entre seus objetivos, primordialmente, a formação de professores, sem descuidar-se, todavia, 
do desenvolvimento da pesquisa, pois do projeto de universidade de Teixeira fazia parte também um núcleo de estudos e de pesquisas educacionais; Utopia Vetada, porque a experiência foi extinta com a prisão de seu idealizador e substituída pela Universidade do Brasil, cujo projeto distanciava-se totalmente da universidade de Anísio Teixeira ${ }^{8}$.

Diante da frustração dos ideais de Anísio Teixeira identifico um exemplo de manifestação de poder autoritário, de arbitrariedade e de dominação na história da educação brasileira, agora sob o jugo do Estado Novo de Getúlio Vargas. Nesse governo, o centro de referência de formação de professores com o preparo especifico do "professor primário" na universidade não logrou êxito. A Escola Normal continuou sendo o locus principal de preparo desse professor. O nível superior foi reservado, exclusivamente, para formar o professor do secundário, inclusive o professor da Escola Normal.

Formar o "professor primário" em nível superior em 1935, como desejava Anísio Teixeira, sem dúvida, evidenciava uma concepção ideal de formação numa época em que não existia sequer número suficiente de professores formados pelas escolas normais para dar atendimento à demanda do ensino primário.

De acordo com Chagas (1992) ${ }^{9}$, a identidade do curso de pedagogia encontra-se no projeto de Escola de Professores, idealizada por Anísio Teixeira, cuja prioridade seria formar "professores primários" com nível superior. Chagas argumenta que a formação de docentes para o início da escolarização implica aprofundamentos de estudos, que não se esgotam nos currículos da Escola Normal. Segundo esse entendimento, a formação de "professores primários" constitui a identidade conferida ao curso de pedagogia.

Apesar dessa evidência, o curso de pedagogia, criado oficialmente no Brasil em 1939, não assumiu essa identidade. Ela voltará ao cenário das políticas de formação de professores, nos idos de 70 . Essa fase da história do curso ainda será analisada neste artigo.

Em 1939, durante o Estado Novo, institui-se, como locus de formação de professores a Faculdade de Filosofia, Ciências e Letras, obrigada a uma estruturação curricular baseada no chamado esquema $3+1$, segundo o padrão federal universitário. Esse esquema impôs para a formação de professores um ano de Didática, além do bacharelado das áreas específicas do saber. O bacharelado em pedagogia formava o técnico em educação, cuja função no mercado de trabalho nunca foi claramente definida. Curioso é que o técnico em educação, para se tornar licenciado e professor da Escola Nor- 
mal, era obrigado a freqüentar o curso de Didática com mais um ano de estudos superpostos ao bacharelado em pedagogia.

A meu ver, essa obrigatoriedade representa uma tautologia denominada "didática da pedagogia", situação estranha que dissociava o conteúdo da pedagogia do conteúdo da didática em cursos distintos, provocando a ruptura entre conteúdo dos conhecimentos específicos e o método de ensinar esse conteúdo. Estabeleceu-se, desse modo, a dicotomia entre conteúdo e método, o que, sob minha ótica, marca a origem da dicotomia entre teoria e prática tão evidente no currículo do curso de pedagogia da atualidade. Essa dicotomia, uma das causas mais recorrentes da formação do pedagogo, levou alguns conselheiros do CNE a golpearem, em 1999, os cursos de pedagogia das faculdades de educação, como supramencionado. Esse golpe excluiu delas o direito já conquistado de qualificar o professor para atuar nas séries iniciais do Ensino Fundamental.

$\mathrm{Na}$ trajetória do curso de pedagogia, desde sua criação ate 1999 , encontra-se pelo menos uma tentativa de o mundo oficial diminuir a distância entre a teoria e a prática. Trata-se do Parecer do CFE n 251/1962, do conselheiro Valnir Chagas que tinha o propósito de reformular o curso de pedagogia. Esse parecer estabeleceu o currículo mínimo no curso de formação do pedagogo e ampliou-o para quatro anos de duração, visando extinguir o esquema $3+1$, com a eliminação do bacharelado e permanência apenas da licenciatura. Na prática, tal esquema não foi extinto. A licenciatura continuou formando dicotomicamente o professor da Escola Normal, ao dedicar a maior parte do curso à sua formação teórica e apenas o último ano à prática de ensino. O curso de pedagogia, até 1969, continuou com essa configuração, quando houve mudança substantiva no locus próprio de formação de professores, marcada pelo advento da lei da Reforma Universitária, Lei no 5.540/68.

A Reforma Universitária atingiu, sobremodo, a Faculdade de Filosofia, Ciências e Letras, mas o fulcro central da reestruturação no sistema de formação de professores foi, sem dúvida, a criação dos diversos institutos de "conteúdos específicos" e da Faculdade de Educação. Repartiu-se, então, a formação de professores em dois loci: de um lado, cada instituto de "conteúdo específico" com responsabilidade pelo bacharelado e pela licenciatura de sua área de saber, de outro, a Faculdade de Educação, a qual coube a formação do pedagogo e a oferta das disciplinas pedagógicas para as licenciaturas.

A dinâmica da Faculdade de Educação e a nova estruturação curricular do curso de pedagogia foi definida pelo Parecer CFE $n^{\circ}$ 252/ 
1969 e pela Resolução CFE nº 02/1969, ambos de Valnir Chagas. Esse conselheiro legalizou a formação do pedagogo, fixando os mínimos de conteúdo e duração do curso, dando maior ênfase à formação do especialista sem exigir a docência como um dos componentes de sua qualificação, mas, contraditoriamente, manteve a exigência de comprovação do exercício do magistério para o egresso da pedagogia receber o diploma de especialista.

A política de formação do pedagogo, expressa nos diplomas legais mencionados no parágrafo anterior, foi instituída sob a égide da ditadura militar. O pleno poder do mundo oficial adotou, então, a política planificada do modelo econômico desenvolvimentista e estabeleceu que fosse feita no curso de pedagogia a formação de professores para a Escola Normal - esta denominada, após 1971, habilitação de magistério de $2^{\circ}$ grau. Instituiu, ainda, a formação dos especialistas, respondendo às exigências do modelo educacional tecnicista. A implantação dessa política foi muito rápida e eficaz, em virtude do controle que o mundo oficial mantinha sobre as relações de poder nos sistemas de ensino. Dessa maneira, o mundo oficial impedia qualquer ação do mundo real, porque, como assinala Foucault (1979, p. 182) o poder do sistema vai "ultrapassando as regras do direito que o organizam e delimitam; ele (o poder) se prolonga, penetra em instituições, corporifica-se em técnicas e se mune de instrumentos de intervenção material".

É importante destacar que, por uma arbitrariedade dos instrumentos de intervenção corporificada nos pareceres do CFE,

os egressos da licenciatura em pedagogia seriam os futuros professores da Escola Normal que formava "professores primários". No entanto, o currículo dessa licenciatura, como o estabelecido em 1939, não contemplava o conteúdo do curso primário. Certamente, os licenciandos aprendiam esse conteúdo por encanto, ou talvez pela "prática", caso o futuro bacharel já fosse professor primário. Essa estruturação do curso de pedagogia facilitou a adoção da premissa "quem pode o mais pode o menos", isto é, se os licenciados em pedagogia estavam habilitados a formar professores de professores primários, por "osmose" adquiririam o domínio dos conteúdos do curso primário. (Brzezinski 1996c, p. 45)

O pedagogo deveria saber fazer uma educação que não tinha aprendido, nem vivido, uma vez que deveria tornar-se professor de 
atuação multidisciplinar sem nunca ter vivenciado a multidisciplinaridade teórico-prática das séries iniciais do Ensino Fundamental.

Felizmente, a partir de 1985, as experiências de reformulacões curriculares do curso de pedagogia que se voltam para a formação de professores para as séries iniciais do Ensino Fundamental vieram corrigir essa distorção e atingiram patamares desejáveis de qualificação, já comprovados pelo bom desempenho dos egressos do curso de pedagogia nos concursos destinados ao preenchimento de vagas para professores de atuação nos anos iniciais da educação básica. Com efeito, as propostas de curso de pedagogia que vêm qualificando esses professores, com um embasamento teórico-prático-teórico pretendem negar qualquer possibilidade de preparo pela falaciosa aplicação da premissa "quem pode o mais pode o menos", como era feito no antigo curso de pedagogia. Nesse sentido, o educador deveria ser, fazer e saber fazer, tendo uma identidade configurada pela e na sua formação da qual foi co-autor.

Felizmente, também, ainda, no Parecer $n^{\circ}$ 161/86, intitulado "Reformulação do curso de pedagogia", além de fazer um histórico do curso e das regulamentações feitas pelo CFE, a conselheira Eurides Brito da Silva aponta os projetos de reformulação apresentados para análise no Conselho e sugere que devem ser estimuladas experiências de formação, como por exemplo a ênfase na docência para as séries iniciais do Ensino Fundamental, às quais o CFE não pretendia obstar. Isso ocorreu na prática até 1995, quando foi instituído o Conselho Nacional de Educação, pela Lei no 9.193 .

É licito lembrar, contudo, que a sugestão dada por Brito (1986) não era novidade no âmbito do CFE. Desde o início dos anos 70, a tônica dos pareceres de Chagas era a de que a concepção de Teixeira (1935) sobre formação de professores fosse concretizada progressivamente até que os professores das séries iniciais do Ensino Fundamental passassem a ser formados em nível superior.

Foi também na década de 1970 que Valnir Chagas teve suas Indicações $n^{\circ} 67, n^{\circ} 68 / 76, n^{\circ} 70$ e $n^{\circ} 71 / 76$ aprovadas no CFE. Essas indicações propunham a reformulação estrutural da formação de professores em nível superior e apontavam para a extinção do curso de pedagogia tal qual se apresentava naquele momento. Essas indicações, que consistiam de "um pacote pedagógico", foram sustadas pelo ministro da Educação da época - Ney Braga, coronel da polícia militar do Paraná e representante da ditadura. Essas indicações eram inoportunas, em face 
do contexto político em que se vislumbrava uma pequena "abertura política" e no qual os movimentos sociais davam mostras de sua marcante existência na clandestinidade.

Ocorre que a aprovação do "pacote pedagógico" pelo CFE foi recebida pelos educadores como mais uma arbitrariedade do poder que desconhecia as práticas, as pesquisas e os estudos desenvolvidos pelos profissionais em seu cotidiano. Sentindo-se ameaçado pelas indicações, o movimento de educadores foi estimulado a manter a resistência ao mundo do sistema, o que levou o mundo real a definir que a docência constitui a base de identidade profissional de todo educador.

Como já afirmei, ancorada em resultados de pesquisa (Brzezinski 1996c), a docência como base de formação do pedagogo vem sendo definida como parte da identidade desse profissional. Essa busca de identidade vem sendo feita pelo curso de pedagogia das faculdades de educação das universidades públicas, que se centram em uma das postulações de Saviani (1976), qual seja: a formação do professor e do especialista no educador, com o que concorda o Movimento Nacional de Educadores.

Ressalto que essa base da identidade do pedagogo centrada na docência foi definida pelas experiências encetadas nas universidades públicas, desde 1985, e, nos anos 90 , foi tomando corpo em diversas propostas das universidades católicas.

Não se pode ignorar também que a organização do sistema de Ensino Superior privado no país, desde as primeiras décadas do século $X X$, reforça o significativo papel de suas escolas na formação de profissionais da educação, que, como está comprovado, salvo raras exceções, não são os melhores exemplos de qualificação.

Apesar desse quadro, o fato de que nem todas as faculdades de educação assumam a docência como base da identidade da formação do pedagogo, com ênfase na formação do professor para as séries iniciais do Ensino Fundamental, não constitui razão suficiente para que os relatores do Parecer CNE/CES nº 970/99 afirmem de modo arbitrário:

há séria lacuna resultante da inexistência de cursos para a formação dos docentes das Sief (Séries Iniciais do Ensino Fundamental) e El (Educação Infantil). Os cursos de pedagogia procuraram suprir esta deficiência e passaram a oferecer uma 
habilitação para a formação de professores desses níveis de ensino. (Parecer CNE/CES no 970, p. 2)

Os fatos demonstram que não são poucas as arbitraridades cometidas pelo CNE desde a homologação da atual LDB, Lei $n^{\circ}$ 9.394/96. Essas atitudes vêm provocando sérias crises internas nesse Conselho, de modo especial quando se travam embates entre os conselheiros que defendem a escola pública, a valorização e a profissionalização do magistério e os que são adeptos da privatização da educação, porque são subordinados aos modelos imperativos do Banco Mundial.

Não são poucas também as intervenções do mundo do sistema nas políticas de formação de profissionais da educação, haja vista a quantidade de pareceres, resoluções, portarias ministeriais e decretos presidenciais sobre o assunto. Muitas delas já tratei em outros estudos, entre tantas, a própria política de formação de professores ${ }^{10}$ estabelecida pela nova LDB/96.

De minha ótica, as intervenções do mundo oficial que mais interessam para o presente artigo são os Pareceres CNE/CES nº 01/99 e n ${ }^{\circ}$ 970/99 e o Decreto Presidencial no 3.276/99. Eles dispõem, respectivamente, sobre as "diretrizes curriculares para a formação de professores na Modalidade Normal em nível médio", sobre o "Curso Normal Superior e a habilitação para magistério em Educação Infantil e séries iniciais do Ensino Fundamental nos cursos de pedagogia" e "sobre a formação em nível superior de professores para atuar na educação básica, e dá outras providências".

A propósito, inicio minha análise sobre esse conjunto denunciando que essas imposições legais se colocam contra as reivindicações do mundo real, representado pelo Movimento Nacional de Educadores, e materializam a violência do poder do mundo oficial que atinge diretamente o ponto extremo do sistema educacional - a escola de educação básica.

A respeito dessa materialidade da violência do poder, compartilho as idéias de Foucault (1979). De acordo com elas, esse conjunto de imposições evidencia a prova da capilarização do poder que deseja penetrar em todas as extremidades e nas últimas ramificações, em detrimento dos que não detêm tal poder. Estes, para Poulantzas (1977), não detêm o poder de legislar, e sim possuem o domínio do poder de luta. Tal domínio os fortalece cada vez mais, na medida em que o mundo vivido tem como prática a conquista da cidadania, mediante uma resistência ativa. Essa resistência, 
dinamicamente, ressignifica-se e se reanima a cada arrefecimento provocado pelos golpes do mundo oficial.

O Parecer CNE/CES no 01/99 consiste um desses golpes. Esse parecer, relatado pela conselheira Edla de Araujo Lira Soares, atingiu o Movimento Nacional de Educadores que, reiteradas vezes, declarou reconhecer somente o nível superior como nível mínimo de formação de profissionais de educação. O parecer, ao contrário, centra-se, a rigor, no que está prescrito no art. 62 da Lei 9.394/96:

a formação de docentes para atuar na educação básica far-se-á em nível superior, em curso de licenciatura, de graduação plena, em universidades e institutos superiores de educação, admitida, como formação mínima para o exercício do magistério na Educação Infantil e nas quatro primeiras séries do Ensino Fundamental, a oferecida em nível médio, na modalidade Normal. (Grifos meus)

Segundo a relatora, esse parecer "além de tudo, possibilita ao poder público proceder à passagem de formação inicial de nível médio para a de nível superior, sem prejuízo da expansão da Educação Infantil e da universalização do Ensino Fundamental" (Parecer CNE/CES nº 01/99, p. 24).

Discordo da posição da relatora, pois, em outra parte do parecer, ela justifica a importância desse nível de formação profissionalizante para equacionar o problema dos leigos do sistema de ensino, que não possuem sequer a formação na modalidade Normal. Ora, segundo consta, esse parecer se propõe a definir diretrizes curriculares para formação inicial de professores na modalidade Normal. Ele não foi elaborado para favorecer, a meu ver, de modo equivocado, o desenvolvimento da "formação continuada" de leigos, como insiste o mundo oficial. Destaco que, na concepção "praticista" do mundo do sistema, a simples prática no Ensino Fundamental constitui a formação inicial desses leigos, sendo dispensável o preparo do docente em cursos regulares de formação.

Apesar desses descompassos, é preciso reconhecer que o parecer apresenta um discurso bastante interessante, uma vez que se ancora em boa fundamentação teórica e dá realce às preocupações das associações e dos sindicatos de professores quanto à profissionalização do educador. No entanto, os termos gerais do parecer estabelecem perfeita sintonia com o que quer o mundo oficial e mantêm coerência com as demais diretrizes curriculares nacionais para o Ensino Médio, Ensi- 
no Fundamental e a Educação Infantil. Não resta dúvida de que tais sintonia e coerência fazem parte do mosaico legislativo que o mundo oficial vem montando para, sub-repticiamente, atender aos condicionantes impostos para as políticas educacionais definidas pelo Banco Mundial.

O que o mundo real deseja - e, para tanto, luta - é que não se instale esse nível de formação e que tampouco se retire do curso de pedagogia o direito de também formar professores para as séries iniciais do Ensino Fundamental e para a Educação Infantil. Ou ainda que o objeto do parecer em tela passe a servir de pretexto para respaldar legalmente a criação de cursos a distância de certificação (e não quelificação) de leigos, como tem sido efetivado com recursos do Fundef nas regiões Norte e Nordeste. Diante disso, as associações de pesquisadores e professores têm voz uníssona ao denunciar que esse parecer é inaceitável pelo mundo vivido.

No que concerne ao Parecer CNE/CES n 970/99, relatado pelos conselheiros Eunice Ribeiro Durham, Yufo Okida e Abilio Afonso Baeta Neves, recorro a uma análise histórica e epistemólogica, realizada neste artigo, para asseverar que o parecer, por um lado, tem mérito por definir uma política de formação do professor da Educação Infantil e das séries iniciais do Ensino Fundamental; por outro, merece repúdio por:

- $\quad$ estimular a vaidade de alguns que detêm o poder para desqualificar as faculdades de educação, por não as reconhecerem como locus para formar o professor da Educação Infantil e o professor das séries iniciais do Ensino Fundamental;

- configurar-se como arbitrário, pelo fato de desrespeitar a autonomia das universidades que apresentaram propostas ao MEC/SESu, a fim de subsidiar a Comissão de Especialistas do Ensino de Pedagogia (Ceep), na elaboração de diretrizes curriculares para a formação dos profissionais da educação, a serem encaminhadas ao CFE. A formação do professor para as séries iniciais do Ensino Fundamental está presente na totalidade das propostas do curso de pedagogia.

- mostrar-se autoritário, por violentar decisões da Ceep, integrada por profissionais que possuem um inquestionável domínio epistemológico, acadêmico, didático e prático para decidir, com o conjunto de profissionais atuantes nas faculdades de educação e similares, quem, o que e como se forma no curso de pedagogia. Os integrantes da Ceep são legítimos representantes do mundo vivido. São professores-pesquisadores nas faculdades e 
nos centros de educação e desenvolvem projetos que os vinculam organicamente às escolas da educação básica. Portanto, eles conhecem as diversas instâncias formadoras, porque nelas estão inseridos. No meu entendimento, a Ceep é autoridade no assunto, pois seus integrantes atuam de fato na universidade e na escola básica, não apenas falam sobre elas ${ }^{11}$, como alguns burocratas de plantão, que passaram pela escola básica e pela universidade somente quando freqüentaram os bancos escolares na condição de alunos;

- $\quad$ apresentar equívocos em relação às finalidades do curso de pedagogia, de modo especial, quando seus relatores assinalaram que

historicamente, os cursos de pedagogia foram concebidos como instrumento de formação de pesquisadores e especialistas da educação. Paralelamente, cabia-lhes a formação de docentes das matérias pedagógicas que integravam o currículo dos cursos normais de nível medio. (CFE/CES, Parecer $n^{\circ}$ 970, 1999, p. 2)

Os relatores mostram equívocos, também quando afirmam que:

há séria lacuna resultante da inexistência de cursos para formação dos docentes das Sief (Séries Iniciais do Ensino Fundamental) e El (Educação Infantil). Os cursos de pedagogia procuraram suprir esta deficiência e passaram a oferecer uma habilitação para a formação de professores desses níveis de ensino. Tratou-se, obviamente, de uma solução provisória, destinada a sanar uma lacuna. (CFE/CES, Parecer no 970, 1999, p. 2)

- desrespeitar as indicações sobre a formação do professor da Educação Infantil e das séries iniciais do Ensino Fundamental feitas pelas associações e entidades que se dedicam aos estudos de pedagogia, realizam pesquisas de reformulações curriculares e militam em defesa do direito à educação para todos os cidadãos brasileiros. Agindo assim, os relatores desrespeitam não só os movimentos organizados de educadores, mas os cidadãos brasileiros que têm o direito e precisam ser formados com qualidade acadêmica, metodológica e técnica, com compromisso político e 
com crítica acurada para resistir "à unidade política do bloco de poder sob a égide da classe ou fração hegemônica", ou seja, para fazer frente à hegemonia do sistema oficial ou, como quer Poulantzas (1977, p. 296), para os cidadãos se contraporem à hegemonia das "elites políticas".

Um enfrentamento ao poder das "elites políticas" ou da fração hegemônica sediada no CFE que merece ser divulgado foi a declaração de voto do conselheiro Jacques Velloso, constante do Parecer CFE/CES no 970/99. O professor Velloso, da Faculdade de Educação da Universidade de Brasília, comprometido com a garantia do exercício pleno da cidadania, discordou do voto dos relatores do CNE. Sua declaração de voto dá mostras de sua dedicação às pesquisas sobre políticas educacionais. Além disso, a responsabilidade política, acadêmica e ética com que ele fez a declaração de voto denota seu compromisso com os princípios assumidos pelo Movimento de Educadores Brasileiros.

Nesse instante, é o meu compromisso com os princípios assumidos pelo Movimento de Educadores o que me autoriza a divulgar um documento pessoal, enviado pelo conselheiro Velloso em 07/12/99, no qual ele assim se manifesta:

votei com minhas convicções, como sempre fiz, buscando valorizar a educação pública (pois é em universidades públicas que se situam as melhores experiências e inovações da formação de nossos professores), defender a qualidade do ensino (pois é com o inteligente uso da flexibilidade que podemos incentivá-la, e não com modelos pré-concebidos, por melhor que possa ser sua origem), fortalecer a boa tradição dos cursos de pedagogia (pois é principalmente nos diversos cursos de pedagogia, sobretudo nas universidades, que está a liderança do pensamento educacional no país, ainda que muitos dos nossos cursos precisem passar por substancial revisão quanto a concepção, corpo docente etc.) e evitar modelos institucionais únicos, de passado com tão danosas e conhecidas conseqüências. (p. 1)

Enfatizo a relevância de um, dentre tantos trechos da declaração de voto em tela, que, embora longo, merece ser transcrito: 
A LDB não proíbe que os cursos de pedagogia, quando ministrados em universidades, habilitem para a atuação em El (Educação Infantil) e Aief (Anos Iniciais do Ensino Fundamental). O Parecer 115/99, que trata dos ISEs (Institutos Superiores de Educação), tampouco impede, sabiamente, que estes cursos cumpram tal finalidade, quando oferecidos por universidades. (Grifos do autor)

Na boa hermenêutica, quando são interpretadas as leis, tudo o que estas vedam em sua letra ou em seu espírito é proibido. De modo análogo, tudo o que estas não vedam em sua letra ou em seu espírito é permitido. Se isso é verdade para toda e qualquer lei, tanto mais o é para a LDB, que tem em sua espinha dorsal a diretriz da flexibilidade e o convite à inovação (grifos do autor), sempre resguardada a qualidade de ensino - esta pela via da comedida supervisão do Estado sobre os fatores iniciais da oferta do ensino da enfática avaliação dos resultados. Efetivamente, não cabe proibir aquilo que a LDB permite, porque não veda. (Grifo meu)

Finalmente chego à análise de mais um instrumento do conjunto de imposições legais que materializam a violência do poder do mundo oficial - o Decreto Presidencial no 3.276, de 6/12/99.

A fração hegemônica do poder político no CNE, apoiada pelo ministro da Educação, foi a inspiradora desse ato autoritário do Presidente da República - o de baixar o decreto que, entre outras providências, cassa $o$ direito de o curso de pedagogia formar professores para atuar nas séries iniciais do Ensino Fundamental e na Educação Infantil, atribuindo essa prerrogativa, com exclusividade, aos Cursos Normais Superiores (art. $\left.3^{\circ}, \S 2^{\circ}\right)$.

Na referida fração hegemônica não figuram os professores Carlos Roberto Jamil Cury, Edla Soares, Hésio de Albuquerque Cordeiro, Jacques Velloso, João Monlevade, Kuno Paulo Rohden, Regina de Assis e Silke Weber, que se mantiveram coerentes com a expectativa de corresponder às posições das entidades da sociedade civil que os indicaram como membros do CNE. Eles se manifestaram, em 8/12/99, quando decidiram endereçar uma carta às universidades, sociedades científicas e entidades profissionais relacionadas à educação. A carta revela que "o caráter colegiado do CNE não somente comporta conflitos entre seus pares como na relação com o Executivo, ao qual cabe homologar os pareceres do conselho e de suas câmaras" (p. 1). Todavia, os conseIheiros foram surpreendidos com a comunicação de que fora publicado 
o decreto ${ }^{12}$, justamente no início da reunião do Conselho Pleno de 7/12/ 99, em que estava pautada a polêmica discussão sobre o assunto, objeto do referido decreto $\mathrm{n}^{\circ} 3.276$.

Nos termos finais da carta, os conselheiros tomam partido em favor do mundo real e se manifestam da seguinte forma:

nós, membros do Conselho Nacional de Educação, abaixo assinados, consideramos inoportuna a publicação do Ato do Executivo, que interrompe, assim, uma discussão em curso e corre o risco de inibir o desenvolvimento e a consolidação de experiências exitosas de formação em inúmeras universidades. (p. 1)

Diante dessa atitude, que renega a disputa pelo poder, os conseIheiros que assinam a carta são aplaudidos pelo mundo real dos educadores, enquanto o mundo oficial poderá ameaçá-los com a cassação de seus mandatos.

Com esse decreto a fração dos conselheiros arraigados ao poder do mundo do sistema tentaram arrefecer o polêmico debate sobre os loci de formação de profissionais da educação, definindo autoritariamente que "a formação em nível superior de professores para atuação multidisciplinar, destinada ao magistério na Educação Infantil e nos anos iniciais do Ensino Fundamental, far-se-á exclusivamente em cursos normais superiores" (art. $3^{\circ}, \S 2^{\circ}$ ).

Pela pressa com que foi publicado o decreto, suspeito que o mundo do sistema estava com receio da vitoriosa conquista, que com certeza está para se materializar, como conseqüência da luta empreendida pelo mundo real.

\section{Algumas considerações finais}

Diante do que foi tratado aqui acerca dos embates na definição da política de formação de professores de atuação multidisciplinar no magistério dos anos iniciais do Ensino Fundamental, não é difícil chegar à conclusão de que há uma disputa de poder das "elites políticas" do mundo oficial, que desejam manter sua autoridade a qualquer preço, 
mesmo que seja para desrespeitar o direito à cidadania coletiva do mundo real. Essa postura do mundo oficial pressupõe o "poder canalizado" que controla até o comportamento, uma vez que "o arquétipo da sensação de poder é o sentimento pessoal de força ao conseguirmos que outra pessoa se curve a nossa vontade" (Mannheim 1972, p. 71). Estou convicta de que o mundo vivido não se curvará à vontade do mundo do sistema, marcado por atos antidemocráticos surpreendentes advindos de um "regime de exceção".

Quanto ao "regime de exceção", lembro que aprendi com Cardoso (1984), uma década antes de ele ser eleito Presidente da República, que esse regime se caracteriza pelo governo ditatorial associado ao modelo econômico capitalista. É notório que grande parte da população brasileira não aceita esse regime e não se curva diante de suas imposições, pois, na sua vigência criam-se situações favoráveis para o emergir dos movimentos sociais que exibem uma espécie de "invenção de atores". Em uma etapa inicial esses atores fazem resistência, em uma segunda etapa, efetivam uma ação coletiva.

Exemplos dessa ação coletiva são a Carta dos Conselheiros ${ }^{13}$ às Universidades, Sociedades Cientificas e Entidades Profissionais relacionadas à Educação e a instalação em Brasília, em 8/12/99, do Fórum em Defesa da Formação de Professores. Esse fórum publicou uma carta-denúncia assinada por Andes, Anfope, Anped, Anpae, ABT, Cedes, Comissão de Especialistas de Ensino de Pedagogia, Fórum de Diretores das Faculdades/Centros de Educação das Universidades Públicas Brasileiras, Fórum Paulista de Educação Infantil, Fórum Paulista de Pedagogia e Fórum Nacional em Defesa da Escola Pública.

Essa carta-denúncia se reporta ao ato de violência que afronta não só a LDB/96, mas todos os envolvidos no debate democrático sobre a formação de profissionais da educação. Refere-se às graves conseqüências resultantes da aplicação do decreto, quais sejam:

1. remete a formação de professores exclusivamente para cursos aligeirados, de cunho estritamente técnico, segregada da formação geral dos demais profissionais da educação;

2. cria um mercado cativo para as instituições privadas de ensino, com a possibilidade de financiamento público, inclusive com a utilização de verbas do Fundef; 
3. desperdiça uma capacidade instalada, com recursos humanos e materiais financiados ao longo do tempo pelo poder público, como são os cursos de pedagogia das universidades. (p. 1)

Para finalizar, é preciso esclarecer que é importante os profissionais da educação não assumirem a mediocridade do mundo oficial como projeto. Importa reconhecer esse momento como de fecundidade de idéias e práticas. Neste movimento fecundo, as idéias e práticas se ressignificam e se fortalecem para sustentar a ousadia de os educadores levarem adiante, com responsabilidade política e ética, as possibilidades de dar maior significado à sólida formação e à valorização profissional do docente, em todos os níveis e modalidades de ensino.

\section{Notas}

1. Para maiores detalhes deve ser consultado o balanço do primeiro ano do Fundo de Desenvolvimento do Ensino Fundamental e de Valorização do Magistério (Fundef), MEC, mar./99, divulgado pelo coordenador do Fundef em audiência pública sobre o Plano Nacional de Educação, na Comissão de Educação da Câmara dos Deputados, em 12/5/99. Dados recentes sobre o projeto Proformação, que aplica recursos do Fundef para conferir certificados aos leigos, em cursos a distância, estão registrados em "Oportunidade para professores. Proformação habilitará 2.300 docentes em Goiás". Fundescola, Boletim Técnico № 32, ano IV, 1999, p. 11.

2. O eixo central dessa tensão são as relações de poder, que são tomadas por mim sob as matrizes teóricas de Marx, Engels, Lênin e Gramsci. De acordo com Poulantzas (1977), esses autores não produziram um conceito de poder, todavia, delimitaram-no ao campo das práticas de classe (práticas essas, das classes sociais do sistema capitalista), uma vez que "as relações entre as classes são relações de poder" (p. 95). Para tratar das relações de poder na escola baseie-me em Weber (1991), tido como o fundador da sociologia política ou sociologia do poder, que relaciona o conceito de poder ao de dominação e também vali-me dos ensinamentos de Foucault $(1979,1989)$. Alerto que uma boa referência acerca das relações de poder na escola é encontrada em Resende (1995).

3. A expressão "professor primário" é tomada para denominar o professor de atuação multidisciplinar no ensino primário. Era de uso corrente nessa época. Essa denominação foi modificada para "professor de $1^{\circ}$ grau", com a lei 5.692/71. Essa nova denominação, por sua vez, foi alterada para "docente para as primeiras séries do Ensino Fundamental" pela atual LDB da Educação Nacional, Lei no 9394/96 (Cf. art. 63, inciso I). 
4. Conforme estudos que realizei em meu doutoramento (1994), essas "cadeiras" constituem as raízes do curso de pedagogia das atuais faculdades de educação e similares.

5. Monarca (1999) realizou um estudo aprofundado sobre a Escola Normal de Estudos Pedagógicos, criada pela Lei Provincial no 34/1846 e instalada em uma sala da do edifício da Catedral da Sé na cidade de São Paulo, sendo destinada a estudantes do sexo masculino, com idade mínima de 16 anos, livres e de bons costumes.

6. O método de ensino mútuo ou lancasteriano foi introduzido na Inglaterra, em 1797, por Andrew Bell e desenvolvido por Joseph Lancaster. Consiste de um método em que, por meio de monitores e com um número suficiente de "decuriões" escolhidos entre os estudantes mais adiantados, um único professor dirigia a instrução de centenas de alunos. Maiores esclarecimentos sobre o assunto podem ser encontrados em Larroyo (1970).

7. A divulgação dessas experiências tem sido feita sistematicamente pela Anfope. Nos momentos mais recentes são feitas também manifestações a esse respeito nos documentos do Fórum de Diretores de Faculdades/Centros de Educação das Universidades Públicas Brasileiras.

8. Cf. Paim 1981.

9. Informações obtidas em uma conversa informal com Valnir Chagas, estudioso do curso de pedagogia e conselheiro no CFE por mais de duas décadas.

10. Marilena Chauí (1980), com base nos ensinamentos de Claude Leford, faz uma profunda análise filosófica sobre esse assunto.

11. Decreto de 19/8/97 que regulamenta, para o Sistema Federal de Ensino, as disposições contidas no art. 10 da Medida Provisória no 1.477-39, de 8/8/1997, e nos arts.16, 19, 20, 45, 46 e $\S 1 \stackrel{0}{5} 52$, parágrafo único, 54 e 88 da Lei no 9.94/96, de 20/12/1996, e dá outras providências.

12. Este foi expedido "sob a alegação de que no Decreto 2.306/97 havia restado uma lacuna interpretativa do texto da LDB sobre o ensino superior" (p. 1).

\title{
Opposition concerning the definition of the teachers formation for the multidisciplinary acting in the early years of elementary school. Is it respect to citizenship or dispute of power?
}

\begin{abstract}
The article shows the modern opposition between the official world and the real world related with the policies of teachers formation for basic education, especially for the policies of teachers formation for the initial grades of elementary school. In this article there's a search for alternatives concerning the question: Do these
\end{abstract}


oppositions express respect to citizenship or constitute dispute of power?This same search required na incursion through policies history, of the institutions and of the courses that in the standard pattern, it's been forming teachers to act multidisciplinary in elementary school in our country. Concurrently, it was necessary a foundation in theoretical support that treat the power relationship present in society and in Brazilian schools, which live with the existence of two well defined worlds: the world of the system and another one that's really lived. Such dichotomy is proper from modern societies, and pressupose an interaction game between these worlds, consisting of a powerful and dynamic struggle between the coaction of the political society and the active resistence of the civilian society.

\section{Bibliografia}

ANTUNHA, Heládio. Universidade de São Paulo: Fundação e reforma. São Paulo: Inep/CRPES, 1974.

AZEVEDO, Fernando. A transmissão da cultura (parte terceira da $5^{\mathrm{a}}$ ed. da obra: "A cultura brasileira"). São Paulo: Melhoramentos, 1975.

BRASIL/PR. Lei $n^{\circ}$ 9.131, de 24/11/1995. Altera dispositivos da Lei $n^{\circ}$ 4024, de 20/12/1961, e dá outras providências. Brasília: Gráfica do Senado, 1995.

. Lei $\mathrm{n}^{\circ} 9.394$, de 20/12/1996. Estabelece as diretrizes e bases da educação nacional. Diário Oficial da União. Brasília: Gráfica do Senado, ano CXXXIV, nl. 248, 23/12/96, pp. 27833-27841.

Decreto $n^{\circ}$ 2.306, de 19/8/1997. Regulamenta, para o Sistema Federal de Ensino, as disposições contidas no art. 10 da Medida Provisória $\mathrm{n}^{\circ}$ 1.477-39, de 8/8/1997, e nos arts.16, 19, 20, 45, 46 e $\S 1^{\circ}$, 52, parágrafo único, 54 e 88 da Lei nº 9.394/96, de 20/12/1996, e dá outras providências. Brasília: Gráfica do Senado, 1997. (Mimeo.)

. Decreto no 3.276 , de 6/12/1999. Dispõe sobre a formação em nível superior de professores para atuar na educação básica, e dá outras providências. Diário Oficial da União. Brasília: Gráfica do Senado, 7/12/99.

BRASIL/MEC. Portaria Ministerial n 181, de 23/2/96 que estabelece diretrizes para autorização e reconhecimento de cursos. Brasília, 1996. (Mimeo.) 
. Balanço do primeiro ano do Fundef. Brasília: MEC, mar. 1999. . Banco Mundial. Fundescola. Projeto Nordeste. Boletim Técnico no 32. Ano IV, 1999.

. Minuta de Portaria de 11 de dezembro de 1996. Brasília, Gabinete do Ministro, 1996 (Mimeo).

BRASIL/MEC/CNE. Parecer $n^{\circ}$ 4, de 11/3/1997. Apresenta proposta de resolução referente ao programa especial de formação de professores para o $1^{\circ}$ e $2^{\circ}$ graus de ensino - Esquema 1. Brasília, 1997. (Mimeo.)

. Parecer CNE/CEB no 01/99. Diretrizes curriculares para a formação de professores na Modalidade Normal em Nível Médio. Brasília: CFE, 1999. (Mimeo.)

. Parecer CNE/CES no 970/99. Curso Normal Superior e da Habilitação para Magistério em Educação Infantil e Séries Iniciais do Ensino Fundamental nos cursos de Pedagogia. Brasília: CFE, 1999. (Mimeo.)

. SESu/CEE/PEDAGOGIA. Parecer $n^{\circ} 361 / 96$. Trata do registro simultâneo aos licenciados em pedagogia da Universidade Federal Fluminense, Processo $\mathrm{n}^{\circ}$ 23000.00658195-13. Brasília, s.d. (Mimeo.)

. SESu/CEE/PEDAGOGIA. Processo nº 23001.00006319677. Trata da proposta de reformulação do curso de pedagogia da Universidade Federal do Paraná. Brasília, 22/10/96. (Mimeo.)

BRZEZINSKI, Iria. A formação do professor para o início de escolarização. Goiânia: Editora UCG, 1987.

. "Pedagogia, pedagogos e formação de professores. Busca e movimento". Tese de doutorado. São Paulo: USP, 1994.

. "Desafios à implementação de uma política de formação de professores: Salário, estrutura de carreira, habilitação e qualificação". Boletim Anfope. Campinas: Anfope, ano 11, ri. 2, jun. 1995, pp. 3-12.

. "Rumos da formação dos profissionais da educação face às novas demandas educacionais e sociais no contexto contemporâneo". Recife: VII Encontro Regional da Anfope do Nordeste, 1996a. (Mimeo).

BRZEZINSKI, Iria (coord.). "Documento gerador do VIII Encontro Nacional da Anfope". Goiânia, 1996b. (Mimeo). 
- Pedagogia, pedagogos e formação de professores. Busca e movimento. Campinas: Papirus, 1996c.

. "A questão da qualidade: Exigência para a formação dos profissionais da educação". Revista Brasileira de Administração da Educação (Anpae) nº 1. Brasília, v. 12, jan./jun. 1996d, pp. 110-123.

. (org). LDB interpretada. Diversos olhares se entrecruzam. $2^{\text {a }}$ ed. São Paulo: Cortez, 1997.

BRESSER PEREIRA, Luis Carlos. "A diferença está no debate". Folha de S. Paulo, C1, F3. 20/12/99.

CARDOSO, Fernando Henrique. "A democracia na América Latina". Novos Estudos no 10. Out. 1984, pp. 45-56.

CHAGAS, Valnir. "Currículo mínimo e duração do curso de pedagogia. Parecer 251/62". Documenta $\mathrm{n}^{\circ}$ 11. Rio de Janeiro: MEC/CFE, 1963, pp. 95-100.

. "Estudos pedagógicos superiores. Parecer 252/69". Documen$\operatorname{ta~} \mathrm{n}^{\circ}$ 100. Rio de Janeiro: MEC/CFE, 1969, pp. 101-112.

. Formação do magistério: Novo sistema. São Paulo: Atlas, 1976.

. "Resolução do CFE que dispõe sobre o preparo dos especialistas e professores de educação". Didata $n^{\circ} 5$, São Paulo: PUC, 1976, pp. 5-22.

. O ensino de $1^{\circ}$ e $2^{\circ}$ graus: Antes, agora e depois?. $4^{\mathrm{a}}$ ed. atualizada com acréscimo de novo capítulo. São Paulo: Saraiva, 1984.

CHAUÍ, Marilena. "Ideologia e educação". Educação \& Sociedade no 5. São Paulo; Campinas: Cortez/Autores Associados/Cedes, jan. 1980, pp. 24-40.

CONARCFE. "Documento Final". I Encontro Nacional da Comissão de Reformulação dos Cursos de Formação do Educador. Belo Horizonte, 1983. (Mimeo.)

. "Documento Final". V Encontro Nacional da Comissão de Reformulação dos Cursos de Formação do Educador. Belo Horizonte, 1990. (Mimeo.)

CURY, Carlos Roberto Jamil et alii. Carta às Universidades, Sociedades Cientificas e Entidades Profissionais relacionadas 'a Educação. Brasília, 8/12/99. (Mimeo.) 
FERNANDES, Florestan. "Formação de profissionais especialistas nas faculdades de filosofia". Revista Brasileira de Estudos Pedagógicos nº 85 . Rio de Janeiro: MEC-Inep, v. 37, jan./mar. 1962, pp. 227-233.

"Diretrizes e bases: Conciliação aberta". Educação \& Sociedade $\mathrm{n}^{\circ}$ 36. Campinas: Cedes, ano XI, ago. 90, pp. 142-149.

FÉTIZON, Beatriz Alexandrina de M. "Subsídios para o estudo da Universidade de São Paulo". Tese de doutorado. São Paulo: USP, 1986.

FOUCAULT, Michel. Microfísica do poder. Rio de Janeiro: Civilização Brasileira/Graal, 1979.

. Vigiar e punir: História da violência nas prisões. Petrópolis: Vozes, 1989.

FÓRUM EM DEFESA DA FORMAÇÃO DE PROFESSORES. "Denúncia. Governo intervém na formação de professores por decreto". Brasília, 8/ 12/99. (Mimeo.)

GADOTTI, Moacir. Educação e poder: Introdução à pedagogia do conflito. São Paulo: Cortez/Autores Associados, 1980.

GRAMSCI, Antonio. Maquiavel, a política e o Estado moderno. $5^{\mathrm{a}}$ ed. Rio de Janeiro: Civilização Brasileira, 1984.

LARROYO, Francisco. História geral da pedagogia. São Paulo: Mestre Jou, 1970.

LEME, Paschoal. "O manifesto dos pioneiros da educação nova e suas repercussões na realidade educacional". Revista Brasileira de Estudos Pedagógicos nํ 150. Brasília: MEC-Inep, v. 65, maio/ago. 1984, pp. 255-272.

MANNHEIM, Karl. Liberdade, poder e planificação democrática. São Paulo: Mestre Jou, 1972.

MENDONÇA, Ana Walesca P.C. "Universidade e formação de professores: Uma perspectiva integradora. A Universidade de Educação de Anísio Teixeira". Tese de doutorado. Rio de Janeiro: PUC, 1993.

MONARCA, Carlos. Escola Normal da Praça: O lado noturno das luzes. Campinas: Ed. da Unicamp, 1999.

MOACYR, Primitivo. A instrução e o império. Rio de Janeiro: Cia Ed. Nacional, 1938.

PAIM, Antonio. A UDF e a idéia de universidade. Rio de Janeiro: Tempo Brasileiro, 1981. 
POULANTZAS, Nicos. Poder político e classes sociais. Trad.. Francisco Silva. São Paulo: Martins Fontes, 1977.

RESENDE, Lúcia Maria Gonçalves de. Relações de poder no cotidiano escolar. Campinas: Papirus, 1995.

STIRN, François. Os grandes pensadores contemporâneos. Trad. Alexandre Emílio. Lisboa: Instituto Piaget, s.d.

TEIXEIRA, Anísio. "Uma perspectiva de educação superior no Brasil". Revista Brasileira de Estudos Pedagógicos n 111. Brasília: MEC/ Inep, v. 50, jul./set. 1969, pp. 21-61.

SCHWARTZMAN, Simon. Formação da comunidade científica no Brasil. São Paulo: Companhia Nacional, 1979.

WEBER, Max. Economia e Sociedade. Brasília: UnB, 1991.

YOUNG, Michel. "Bridging the theorylpractice divide: An old problem in a new context”. In: Educational and Child Psychology. Londres, 7(3):1990. 